Physical Disabilities: Education and Related Services, 2015, 34(1), 31-54 doi: 10.14434/pders.v34i1.13823

(C) Division for Physical, Health and Multiple Disabilities

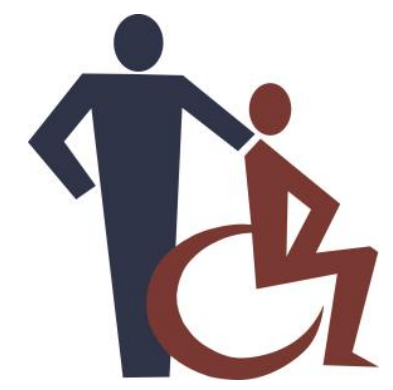

ISSN: 2372-451X

http://scholarworks.iu.edu/journals/index.php/pders/index

Article

\title{
A MODULE-BASED APPROACH: TRAINING PARAEDUCATORS ON EVIDENCE-BASED PRACTICES
}

\author{
M. Alexandra Da Fonte \\ Vanderbilt University \\ Andrea M. Capizzi \\ Vanderbilt University
}

\begin{abstract}
Paraeducators are on the front lines in special education settings, providing support to teachers and students with significant disabilities and specific health-care needs. The important role they play demands efficient and cost-effective training in core skills. This study utilized a multiple-baseline across behaviors design to evaluate a module-based training program for paraeducators targeting three instructional strategies that are commonly used in the education of students with a wide range of disabilities: praise, pause, and prompts. Results demonstrated variability in accurate and consistent use of these practices across participants after completion of the modules. Implications for future research and practice are discussed.
\end{abstract}

Keywords: module-training; paraeducators; professional development 


\section{Introduction}

Paraeducators have an important role in the instruction and support of students with disabilities (Maggin, Fallon, Sanetti, \& Ruberto, 2012; Rispoli, Neely, Lang, \& Ganz, 2011). These responsibilities can vary depending upon the types of students with whom they work. For example, the responsibilities of paraeducators working with students with significant disabilities and specific health-care needs may include providing support in one-on-one activities, using specific instructional strategies (e.g., prompting, pause-time), toileting, and feeding among others. Unfortunately, many paraeducators do not receive training until after they begin working in the classroom (Tompkins et al., 2012). Effective paraeducator training is imperative as paraeducators often perform various tasks within the classroom setting such as making adaptations, implementing behavior change plans, and making on-the-spot instructional decisions for students with special needs (Giangreco \& Broer, 2005; Giangreco, Edelman, Broer, \& Doyle, 2001; Maggin et al., 2012; Tompkins et al., 2012). Moreover, without sufficient training or support, paraeducators may not be effective in their positions and, in turn, have a direct impact on student achievement (Giangreco, Backus, CichoskiKelly, Sherman, \& Mavropoulos, 2003; GriffinShirley \& Matlock, 2004; Rispoli et al., 2011; Tompkins et al., 2012). In fact, Fisher and Pleasants (2012) suggested the role of paraeducators becomes paradoxical as "the least qualified staff are teaching students with the most complex learning characteristics and in some cases with little oversight or direction" (p. 288).

There is evidence of the efficacy of training paraeducators to implement instructional practices and use targeted instructional strategies with students with disabilities (Bingham, Spooner, \& Browder, 2007; Douglas, McNaughton, \& Light, 2013; Feldman \& Matos, 2013; Lane, Fletcher, Carter, Dejud, \& Delorenzo, 2007; Maggin et al., 2012; O’Keefe, Slocum, \& Magnusson, 2013; Quilty, 2007). Effective paraeducator training can allow special education teachers to delegate more responsibilities while simultaneously offering the paraeducator the opportunity to independently carry out the teacher's plans (Douglas et al., 2013; Feldman \& Matos, 2013). Furthermore, paraeducators report that with additional training, they feel more competent and desire to play an integral role in making changes to improve instruction (Carter, O'Rourke, Sisco, \& Pelsue, 2009; Feldman \& Matos, 2013; Giangreco et al., 2003) and with proper training, it has been suggested that paraeducators can increase student learning (Feldman \& Matos, 2013; Maggin et al., 2012; Quilty, 2007; Rispoli et al., 2011).

\section{Type and Purpose of Training}

Special education teachers with whom paraeducators work should be partially responsible for paraeducator training tailored to the school, students, and classroom (Da Fonte \& Capizzi, 2015). Due to the varied responsibilities given to paraeducators in the field, the Council for Exceptional Children (CEC, 2011) developed Paraeducator Professional Development Standards. These guidelines focus on special education concepts and knowledge and skills in performing specific job tasks.

A critical component in paraeducator training is ensuring that training procedures will positively influence paraeducator performance and student outcomes (Fisher \& Pleasants, 2012; Giangreco $\&$ Broer, 2005; Giangreco et al., 2001). In fact, the literature suggests that paraeducators and 
teachers have indicated a preference for training in the areas of: (a) disability specific information, (b) goals and objectives, (c) instructional skills and practices, (d) managing students, and (e) assistive technology (Breton, 2010; Butt \& Lowe, 2012; Carter et al., 2009; GriffinShirley \& Matlock, 2004); areas which are outlined in CEC's Paraeducator Professional Development Standards (2011). Moreover, paraeducators reported feeling more confident in their knowledge and ability to perform tasks in the classroom and work with students with disabilities after receiving training (Carter et al., 2009; Douglas et al., 2013; Feldman \& Matos, 2013; O’Keeffe et al., 2013).

Training for paraeducators can vary across instructional methods. The most common training formats that have shown positive training outcomes include: (a) some form of didactic instruction, such as direct instruction, (b) modeling, (c) rehearsal, and (d) feedback (Bolton \& Mayer, 2008; Brock \& Carter, 2013; Feldman \& Matos, 2013; McCulloch \& Noonan, 2013). In addition, prompting strategies (e.g., Petscher \& Bailey, 2006), coaching (e.g., Duchaine, Jolivette, \& Fredrick, 2011), self-monitoring (e.g., Kalis, Vannest, \& Parker, 2007), and performance feedback (e.g., Reinke, Lewis-Palmer, \& Merrell, 2008) have been used to enhance paraeducator use of various instructional techniques. Didactic instruction, when combined with feedback, has shown more positive outcomes in use and maintenance of skills (e.g., Koegel, Kim, \& Koegel, 2014) than when used in isolation (e.g., Matthews \& Hagopian, 2014). Beyond these methods of training, various forms of technology (e.g., web-based instruction, Microsoft PowerPoint ${ }^{\mathrm{TM}}$ slides, video and audio-streaming) have also been employed to supplement instruction, decrease costs, and expand delivery of training (e.g., Brock \& Carter, 2013; Feldman \& Matos, 2013; Maggin et al., 2012; McCulloch \& Noonan, 2013). This evidence suggests that a cost and timeeffective method involving explicit instruction that allows paraeducators to practice, receive coaching and/or modeling, and receive feedback on the strategies they have learned may be an effective means to train paraeducators.

\section{The Three Ps: Praise, Pause and Prompts}

Regardless of the specific methods used to train paraeducators, it is clear they should be trained to meet their job requirements (e.g., CEC, 2011). While there may be job-specific skills for which paraeducators should be trained; unfortunately, due to busy school schedules and time constraints, teachers and school districts may not be able to provide instruction to their staff members on all strategies. As a result, teachers need to prioritize which skills are essential in the training of the paraeducators to meet students' needs. In this particular case, three key instructional strategies were selected for the focus of this study: praise, pause, and prompts. These strategies were selected because they are widely used as part of instruction in a variety of classroom settings (e.g., Feldman \& Matos, 2013; Johnson \& Parker, 2013; Partin, Robertson, Maggin, Oliver, \& Wehby, 2009) and are commonly used with students with a range of needs such as those with intellectual disabilities, multiple disabilities, and significant health-care needs (Browder \& Spooner, 2011; Ledford, Lane, Elam, \& Wolery, 2012; Westling \& Fox, 2009; Wolery, Anthony, Caldwell, Snyder, \& Morgante, 2002).

Praise. Behavior-specific praise is a positive statement delivered orally immediately after a desired behavior that explicitly specifies the desired behavior in which the student was engaging (Sutherland, Alder, \& Gunter, 2003; Sutherland, Wehby, \& Copeland, 2000). Teachers and 
paraeducators should provide behavior-specific praise that relates directly to the behavior the teacher or paraeducator would like to foster. The use of behavior-specific praise is likely to be effective at increasing desired behaviors for students of all age groups and disabilities (Partin et al., 2009). The rate at which praise statements are delivered has been linked to instructional effectiveness; lower rates of disruptive behavior; and increased student engagement, motivation, achievement, and compliance (Duchaine et al., 2011; Fullerton, Conroy, \& Correa, 2009; Sutherland et al., 2003; Sutherland et al., 2000).

Pause. Pause, also known as pause-time, wait-time or presentation-rate, is a delay in speech after an adult provides an initial directive, gives a direction, or asks a question. Pause-time is often used to prompt an oral or written response, but may also be used when attempting to elicit a physical response after a direction has been given (Ephratt, 2008; Morse \& Schuster, 2004; Walker, 2008). Students with significant needs may require more time to respond to questions or directions, and this strategy may allow them to respond with as little assistance as possible (Johnson \& Parker, 2013). Pause-time lasting longer than three seconds has resulted in more frequent spontaneous student responses, student-posed questions, and longer student responses to teacher-posed questions (e.g., Feldman \& Matos, 2013; Maroni, 2011; Rowe, 1986). The use of extended pause-time (over 10 seconds) has resulted in higher participation rates from students, better academic achievement, more correct responses, increased student communication turns, and fewer problem behaviors (e.g., Johnson \& Parker, 2013; Rhoades, 2013; Tincani \& Crozier, 2008).

Prompts. Prompts are cues or supports provided during instruction to assist someone in the completion of a task/skill that he/she cannot yet complete independently. Most-to-least prompting strategies are often used with students with significant educational needs when they are beginning to learn a new skill (Vuran, 2008; Westling \& Fox, 2009). Least-to-most prompting strategies involve providing students the opportunity to complete a task independently and providing increasing amounts of support when the student requires. This strategy has been found effective in teaching students chained tasks or skills (Aykut, 2012; Westling \& Fox, 2009). In addition, prompting strategies have been used as a main component in training appropriate behavioral skills; increasing independence; and improving communication, social and life skills (Petscher \& Bailey, 2006; van Vonderen \& de Bresser, 2005; Yanardağ et al., 2011) among students with a wide range of needs. Using prompting strategies appropriately and systematically fading prompts is especially important to prevent student over-reliance on adult support (van Vonderen \& de Bresser, 2005; West \& Billingsley, 2005).

This study was guided by the need for training of paraeducators in key instructional practices to support students within various educational settings, as well as to improve outcomes of students with significant needs. This study evaluated a module-based training approach that focused on the three instructional practices of praise, pause, and prompts. The purpose was to determine if paraeducators' accurate use of praise, pause, and prompts in the classroom when working with students with significant disabilities in conjunction with specific health-care needs improved after completing training modules. The following questions guided the research: (1) Does the module-based training improve paraeducators' use of the instructional practices of praise, pause, and prompts in their interactions with students? and (2) Did paraeducators involved in this study value the instruction provided in the module-based training? 


\section{Method}

\section{Setting}

This study was conducted in a single school in a public, urban school district in the southeastern United States. The school provided specialized educational services for students aged 3-22 years who had multiple disabilities including intellectual impairment and significant health-care needs $(n=90)$. School employees included certified special education teachers $(n=18)$, paraeducators $(n=28)$, nursing staff $(n=9)$, and related arts and services providers (i.e., art, music, adaptive physical education, occupational therapy, speech language therapy, and physical therapy; $n=13$ ). Most classrooms had one special education teacher, two paraeducators (i.e., one primary paraeducator and one floating paraeducator), and 7-9 students.

\section{Participants}

After receiving Institutional Review Board approval, participants were recruited by the authors following a 10-minute presentation at the school to the 28 paraeducators on the purpose of the study. Three paraeducators were randomly selected from the six who expressed interest in participating. All three participants were high school graduates who had passed the state paraeducator test required for employment. All participants supported their classroom teachers in various tasks and worked with all the students within their assigned classroom. Common tasks included instructional support as delegated by the classroom teacher, support in material preparation, feeding, and toileting. Although these participants had been in their classroom settings for several years, they had not had explicit training on instructional practices including praise, pause, and prompts.

Amy. Amy was a 53 year-old African American female who worked in an elementary classroom setting. Amy worked with nine students whose ages ranged from six to seven years. Amy had five years of experience as a paraeducator and had been working with the classroom teacher for one year.

Bev. Bev was a 51 year-old Caucasian female who worked in a transition classroom setting. Bev supported seven students whose ages ranged from 18 to 21 years. Bev had four years of experience and had worked with the same classroom teacher all four years.

Cecelia. Cecelia was a 27 year-old African American female who had seven years of experience and had worked with the same teacher throughout this time. She worked in a middle school classroom setting with eight students ranging in age from 13 to 14 years.

\section{Operational Definitions of Dependent Variables}

This study aimed to increase paraeducators' effective/appropriate use of three instructional practices: praise, pause, and prompts. The dependent variables were operationally defined prior to beginning the study.

Praise was defined as a positive comment made to a student that describes the student's behavior 
and is paired with a praise statement and/or gesture (Sutherland et al., 2000). Examples included a verbal description of the behavior paired with a positive statement (e.g., "Thank you for using your spoon, Jack!') and amplification or repetition of a student response paired with a positive statement (e.g., "Yes, today is Monday! Nice job!!"). A non-example would be a vague or general statement such as "Good job!" or "Nice work, Laura!"

Pause was defined as the time an adult waited for a student to respond to a question or directive before providing a prompt or the correct answer (Ephratt, 2008; Morse \& Schuster, 2004; Walker, 2008). Instances of accurate use of pause were coded when five or more seconds of pause were given before asking the question again or rephrasing it. One example provided in the module on use of pause was, "Hannah, how old are you?" with a five-second pause before reframing the question to "Hannah, tell me how old you are." A non-example was calling a student's name to gain his or her attention or to refocus attention such as "David, what color is this apple?" No pause. "Is this apple red?"

Prompt was defined as any adult behavior that was delivered prior to or during a student's attempt to complete a task after the initial instruction was delivered for the purpose of guiding a student to actively participate in a task or behavior (West \& Billingsley, 2005). Use of prompt was counted as accurate if the participant followed a systematic way in providing the student with the support needed (i.e., least-to-most or most-to-least prompting) even if there was no pause-time provided between prompts. The use of prompting was considered accurate when the participant provided systematic support to the student. That is, a directive was given and the student was provided with the opportunity to complete the task independently. In instances where the student gave no response, the paraeducator provided support as previously directed by the classroom teacher (least-to-most or most-to-least). An example of a most-to-least prompt hierarchy was when the adult provided a direction or question (e.g., "Which one is the apple?"), the student did not respond independently, hence the adult delivered full physical assistance to guide the student to select out of a field of two items (apple and banana). An example of least-tomost prompt hierarchy with the same task was when the adult provided the direction or question, the student did not respond independently, so the adult rephrased the initial question or offered a verbal statement to guide the student to the correct answer ("point to apple"). Non-examples included not providing the student with a guide while labeling the skill, task, or behavior being requested.

Data were collected on accurate and inaccurate use of praise, pause, and prompts. For the purpose of this study, accurate use of instructional practices was defined as any time the paraeducator followed the operational definitions as described and exemplified in each of the training modules. Inaccurate use of the behaviors was referred to as paraeducators' inadequate practices of the instructional behavior, use of the non-example behaviors while working with a student, and/or non-use of strategy when appropriate based on the instructional situation. Both accurate and inaccurate responses were recorded to determine total number of opportunities paraeducators engaged in these practices/behaviors within each session.

\section{Independent Variable: Training Modules}

Three modules were developed to train the participants in the effective/appropriate use of praise, 
pause, and prompts. Each training module was created using PowerPoint ${ }^{\mathrm{TM}}$ and followed an explicit instructional model because this method of instruction has been shown to effectively enhance learner outcomes (Englert, Tarrant, \& Mariage, 1992; Goeke, 2009). Modules ranged from 26 to 52 slides that participants navigated through at their own pace. The explicit instructional sequence used for each module was: (a) a case study (i.e., detailed information was provided for a sample student including the student's strengths and areas of needs; the same case study was used throughout each module); (b) definition of the practice with examples and nonexamples (i.e., a detailed definition was provided and specific examples of accurate and inaccurate use of each practice were described); (c) modeling of the practice over several slides (i.e., examples of specific case scenarios were provided and accurate use of each of the practices was described and outlined); (d) guided practice with feedback for participants to engage in the practice accurately; (e) independent practice slides with auditory and visual feedback for selected responses (i.e., each module provided specific examples where the participant had to make a choice of the accurate practice to use; after a selection was made feedback was provided "that is correct, nice selection," "this is incorrect, please try again;" after correct selection was made, an explanation of why the selection was accurate was provided); and (f) a summary of the practice (i.e., a final "dos and don'ts" was provided as a summary for each module; the information provided was similar to that provided on the "tip-sheet"). Visual and auditory supports such as a picture, videos, and auditory feedback (e.g., "Nice job! That's correct!") were provided to enhance the modeling, guided practice, and independent practice sections. Audio and visual feedback was embedded in the PowerPoint ${ }^{\mathrm{TM}}$ slides to indicate when participants selected a correct or incorrect answer.

Data were collected on the length of time each participant took to complete the module. Following completion of the training modules, participants were provided a one-page tip sheet that was created for each module to highlight key components within these practices/behaviors. Tip sheets were designed as a reference for participants to revisit the concepts after completing each module. Each tip sheet followed the same structure and included: (a) a definition of the strategy, (b) characteristics of how to implement the strategy, (c) when the strategy should be used, and (d) examples of accurate use of the strategy. On the day following the completion of the modules, participants were observed by members of the research team and provided corrective feedback on use of the strategies. The intent of the feedback was not to provide any additional instruction in new skills, but simply to reinforce those learned in the modules.

\section{Experimental Design}

A multiple-baseline across behaviors design was used to evaluate the effects of each training module on participants' increased use of targeted practices in the classroom setting. A multiplebaseline design was employed because it offered the possibility to measure multiple traits before and after a treatment without the requirement of withdrawal of treatment (Kennedy, 2005). Training module sessions were delivered in the same order for each participant; first praise, then pause, and lastly prompt. Baseline data were collected on all three behaviors across all three participants until each module was presented. Each module was delivered at the beginning of each full week. The delivery of the module was staggered to evaluate a relation between implementation of the intervention and behavior change for each targeted behavior. 


\section{Procedures}

Training of coders. Two research assistants were trained by the primary investigators to identify accurate and inaccurate use of each strategy using instructional videos of teachers working with students with special needs. Training initially occurred with identification of a single strategy and was then expanded to include simultaneous coding of all three instructional strategies. Training continued until the level of agreement among coders reached $90 \%$ over five consecutive training sessions. During training, research assistants observed 23 videotaped sessions. Their mean interobserver agreement during training was $88 \%$ (range 33\%-100\%) for praise, $82 \%$ (range 44\%-100\%) for pause, and 90\% (range 50\%-100\%) for prompt. Interobserve agreement was evaluated in all phases for each participant and behavior to determine maintenance of agreement between coders.

Baseline. During baseline, participants were observed in the classroom setting prior to training. Data were collected on participants' accurate use of praise, pause, and prompts. The observation period for each participant was selected based on a time during the school day when the classroom teachers indicated participants were actively engaged in instructional support tasks. Baseline data for use of praise were collected until stability was evident (i.e., 4-5 sessions). The praise module was then implemented for all three participants while continuing baseline for use of pause and prompts.

Intervention. The training modules were provided to all three participants in the same order; first praise, then pause, and finally prompts. The procedures were the same for each module. All three participants completed a module on the same day to control for diffusion of treatment.

Each module was delivered at the beginning of each full week and followed the same structure of implementation. Research assistants presented the module to participants in a quiet area of the school library. Participants completed the training individually. Modules were presented on a laptop in which the participant could independently navigate through the slides at her own pace and go back if she wanted to revisit a slide. After completing the module, participants could ask questions of the research assistants. Research assistants answered questions, took notes of the questions being asked, and made sure content was clarified. Finally, the research assistants provided participants with a tip sheet on the corresponding module before ending the session.

The following day, a research assistant observed participants' use of the skill that was the focus of the previous day's module and provided specific performance feedback. Performance feedback was only provided during this single session and included (1) discussion and reflection on implementation of the targeted strategy, (2) sharing of participant's performance data on use of the targeted strategy, (3) behavior-specific praise for correct use of the target strategy, and (4) corrective feedback for incorrect or inconsistent use of the target strategy. The corrective feedback delivery protocol included (a) review of the tip sheet, (b) reflection on how the strategy should be implemented, and (c) specific examples from that day's observation when the strategy should have been implemented. No further performance feedback was provided to the participants during the intervention phase. 


\section{Data Collection}

Data on the three-targeted strategies (praise, pause, and prompts) were collected daily during baseline and again after completion of a module. Participants were observed for one 30-minute session per day, at a consistent time during the school day while they were working with students. The overall data collection process occurred over a 3-month period. Each participant worked with the same students for each observation session and followed a set classroom routine established by the teacher. During the observations, participants worked with students on various targeted, individualized skills such as using a switch, grasping, choice making, requesting, and rejecting. These skills were identified and initially taught by the teacher with the participants providing supplemental practice during classroom lessons as directed by the teacher.

Event recording was used to measure participants' use of each instructional strategy. Whenever an opportunity to provide praise, pause, or prompts arose, research assistants tallied accurate and inaccurate use of the strategies by the participants. The number of accurate uses of the strategies was graphed for each strategy following each observation. The mean of accurate use (calculated as total accurate use divided by total opportunities for use during the 30-minute observation) and rate of use (calculated as accurate use of strategies per minute) were documented (see Table 1 for results).

Table 1

Mean and Rate of Accurate Strategy Use by Phase and Participant

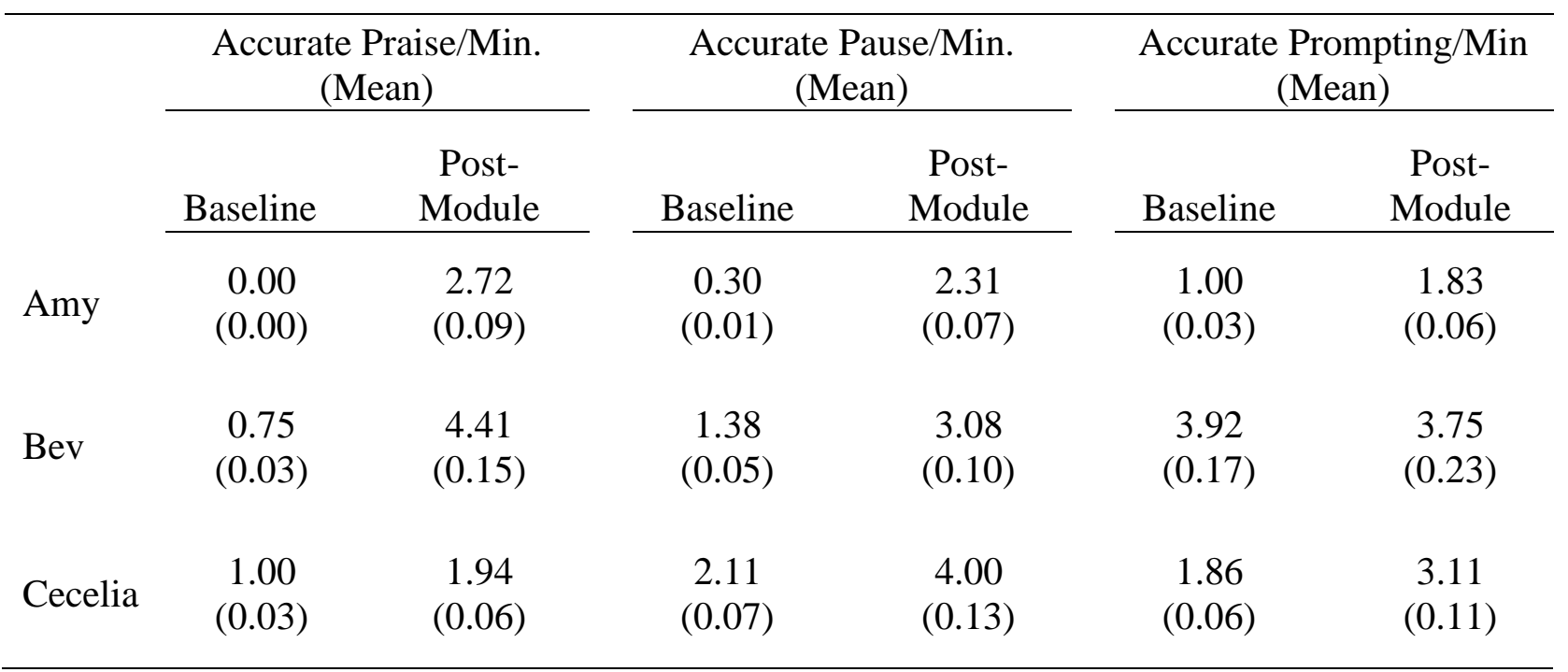

\section{Interobserver Agreement}

During data collection, interobserver agreement data were collected during $36 \%$ of observation sessions distributed across phases and participants. Agreement was consistently above $90 \%$ with a range of $88 \%-100 \%$. 


\section{Procedural Reliability}

During delivery of each training module, research assistants followed both a script and structured guidelines to begin the PowerPoint ${ }^{\mathrm{TM}}$ training module on the computer and supply participants with the tip-sheet. After module delivery, research assistants answered questions and, the following day, provided performance feedback during a single session. A copy of the fidelity checklist was provided to the research assistants to guide implementation. This checklist was used by one of the authors to collect fidelity of implementation data. Fidelity of implementation for module delivery was $100 \%$ across both research assistants. Data were recorded each day of module delivery and during performance feedback.

\section{Social Validity}

Social validity was evaluated to estimate the perceived effectiveness and appropriateness of the module-based training from all participants. The social validity questionnaire was based on the Intervention Rating Profile (IRP-15; Martens, Witt, Elliot, \& Darveaux, 1985). Social validity questions are provided in Table 2. Responses were based on a 3-point scale where 1 represented strongly disagree, 2 was moderately agree, and 3 was strongly agree. Prior to the intervention, participants completed a pre-module questionnaire that took approximately 5-minutes to complete. At the end of the study (approximately seven weeks following initial observations), participants completed a post-intervention questionnaire which included the same items as the pre-module questionnaire, but with tense changed as appropriate. Prior to instruction, participants indicated that they moderately agreed $(M=2.07$, range $1.4-3.0)$ that the training would be helpful. Post-intervention questionnaire results suggested a decrease in participants' perception $(M=1.93$, range $1.4-2.6)$ on the effectiveness of the training.

\section{Results}

Data are provided for Amy, Bev, and Cecelia in Figures 1, 2, and 3 respectively. For each participant, the first leg of the intervention, accurate use of praise, is presented followed by the second leg demonstrating accurate use of pause, and the third leg showing instances of correct prompts used by the participants. Data were evaluated using visual analyses including rapidity of change in strategy use following module implementation, variability in phases, level of behavior, and percentage of non-overlapping data (PND; Scruggs, Mastropieri, \& Casto, 1987), with greater non-overlapping data suggesting greater treatment effects (Scruggs \& Mastropieri, 2013).

\section{Amy}

Praise. During baseline, Amy did not deliver any behavior-specific praise during the five observation sessions. Following delivery of the module, there was an immediate increase in Amy's delivery of praise. Although the level of Amy's instances of behavior-specific praise increased from baseline to intervention, her delivery of praise was quite variable $(M=2.78$, range $=0-8$ across 18 sessions). Even with the high variability, there was $72.22 \%$ PND, demonstrating a change in Amy's use of praise following training. 
Table 2

Social Validity Questionnaire Items ${ }^{1}$

1. This is (was) an acceptable method for enhancing my effectiveness as a paraprofessional.

2. Most paraprofessionals would find this approach appropriate for helping them improve their teaching and effectiveness of their interactions with students.

3. The consultation should prove (was) effective in helping me improve my effectiveness with my students.

4. I would suggest the use of this training to other paraprofessionals.

5. Most paraprofessionals would find the professional development training helpful in enhancing teaching effectiveness.

6. The professional development model would (did) not result in negative side-effects for me.

7. The professional development model is a reasonable way to help paraprofessionals become better more effective with their students.

8. I like(d) the procedures planned for use in the professional development training.

9. The training sessions are (were) a good way to help paraprofessionals enhance their interactions with students.

10. Overall, I believe engaging in the professional development will be (was) beneficial for me.

(Based on the IRP-15 developed by Martens, Witt, Elliott, \& Darveaux, 1985)

${ }^{1}$ Pre-Module questionnaire is provided with Post-Module wording changes in parentheses. Participants rated the items Strongly Disagree, Moderately Agree, or Strongly Agree

Pause. Amy's use of pause was low during baseline observations $(M=0.30$, range $=0-5)$. Postintervention, Amy's use of pause was at a higher level than during baseline $(M=2.39$, range $=$ $0-5)$ and initially showed a steady increasing trend in her use of accurate pause. Her use of accurate pause was quite variable post-intervention, but there were $76.92 \%$ non-overlapping data points.

Prompts. Amy's instances of correct prompting were highly variable during the baseline phase $(M=1.00$, range $=0-4)$ with an increasing trend. Unfortunately, because all participants received training on the same day in order to control for diffusion of treatment, we were unable to take more baseline data to see if her use of prompts stabilized during baseline. Variable use of prompts continued in the post-module phase with a higher level of accurate use of prompts $(M=$ 1.83 , range 1-4). There were no non-overlapping data points between baseline and the post- 
module phase due to high variability in both phases.

Summary. Across legs, Amy's mean use of praise, pause, and prompts increased above baseline levels after completing training. Although she inconsistently implemented praise and pause, the use of these strategies was well above baseline levels, suggesting that Amy may have benefitted from the training modules.

\section{Bev}

Praise. During baseline, Bev's delivery of praise when working with her students was limited ( $M$ $=0.75$, range $=0-2)$. Following implementation of the module, Bev showed a dramatic increase in use of praise $(M=4.13)$, but her instances of praise were quite variable (range 1-10). There were $56.25 \%$ non-overlapping data points between the baseline and post-module phases.

Pause. Prior to receiving the pause training module, Bev's accurate use of pause was low $(M=$ 1.29 , range $=0-2$ ). After implementation of the module, there was an increase in Bev's average use of pause above baseline level $(M=3.02$, range $=1-7)$. Bev's use of pause had an accelerating trend and there were $69.23 \%$ non-overlapping data points.

Prompt. During baseline, Bev's instances of correct prompts were highly variable with a decelerating trend $(M=4.00$; range $=2-7)$. Following training, Bev's use of prompts immediately stabilized, but at a lower level than that of baseline $(M=3.75$, range $3-7)$. There were no non-overlapping data points between baseline and intervention.

Summary. During baseline, Bev demonstrated limited use of praise and pause, and inconsistently used accurate prompts. After training, Bev increased her use of praise and pause, but her accurate use of prompts was unchanged. These results suggest potential influence of the training modules on her use of praise and pause, but not on prompts.

\section{Cecelia}

Praise. Cecelia's instances of accurate praise were variable during baseline $(M=1.20$ range $=0$ 4). Due to the delivery of the modules on the same day for each participant, the baseline phase could not be extended to allow further examination and potential stabilization of data. There were $18.75 \%$ non-overlapping data points between baseline and post-module phases, with an increase in level of instances of accurate use of praise during intervention $(M=2.19)$. Use of praise showed an increasing trend post-module but remained highly variable (range $=0-6$ ).

Pause. During baseline, Cecelia's accurate use of pause was highly variable $(M=2.11$, range = 0-6). Although there were only $9.09 \%$ non-overlapping data points due to high variability in baseline, the level of Cecelia's use of accurate pause increased post-module $(M=4.00$, range $=$ 2-7). After the pause training module, Cecelia's instances of accurate use of pause gradually increased and reached a high point during her final observation session. 


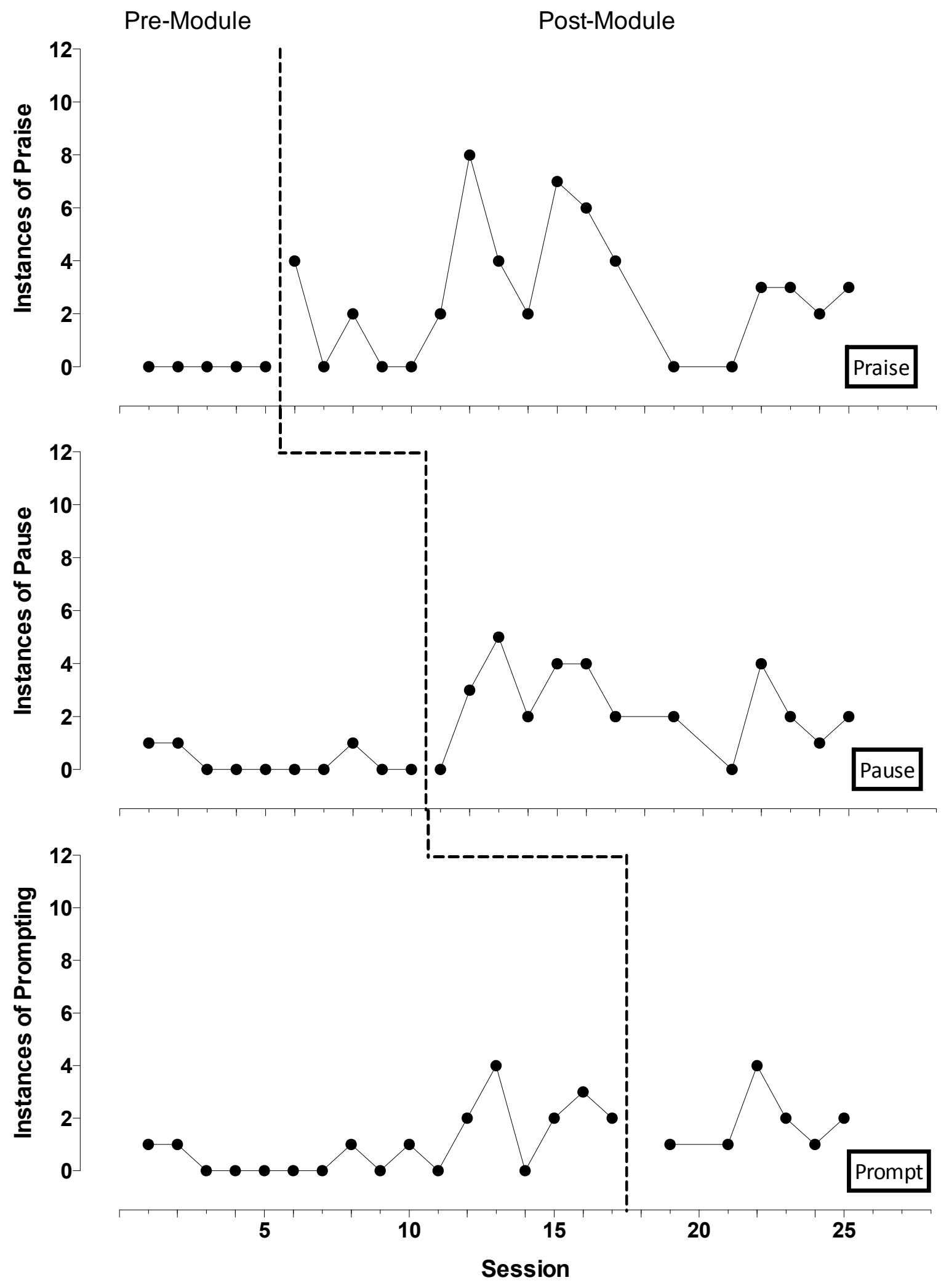

Figure 1. Amy's data. 


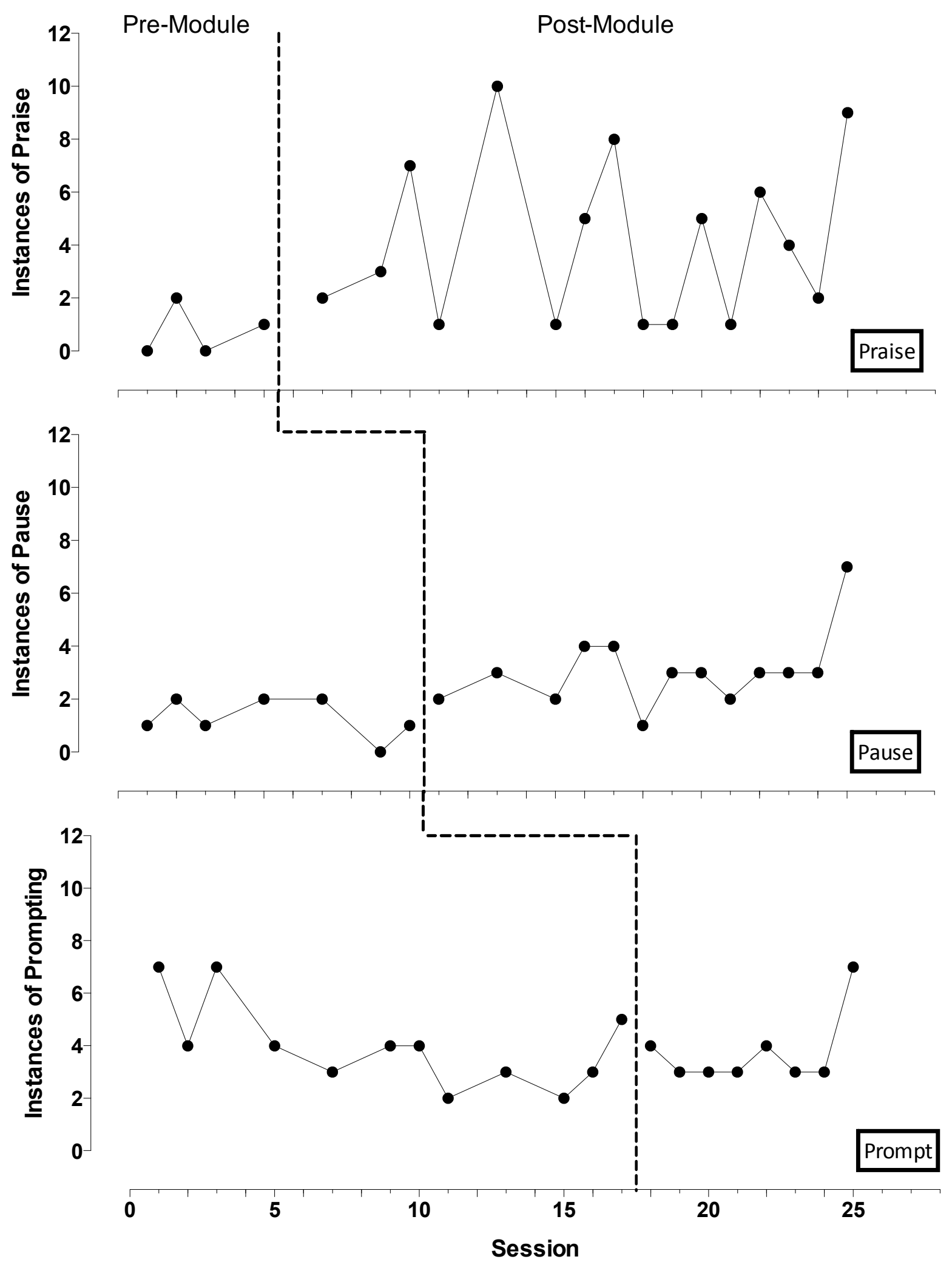

Figure 2. Bev's data. 


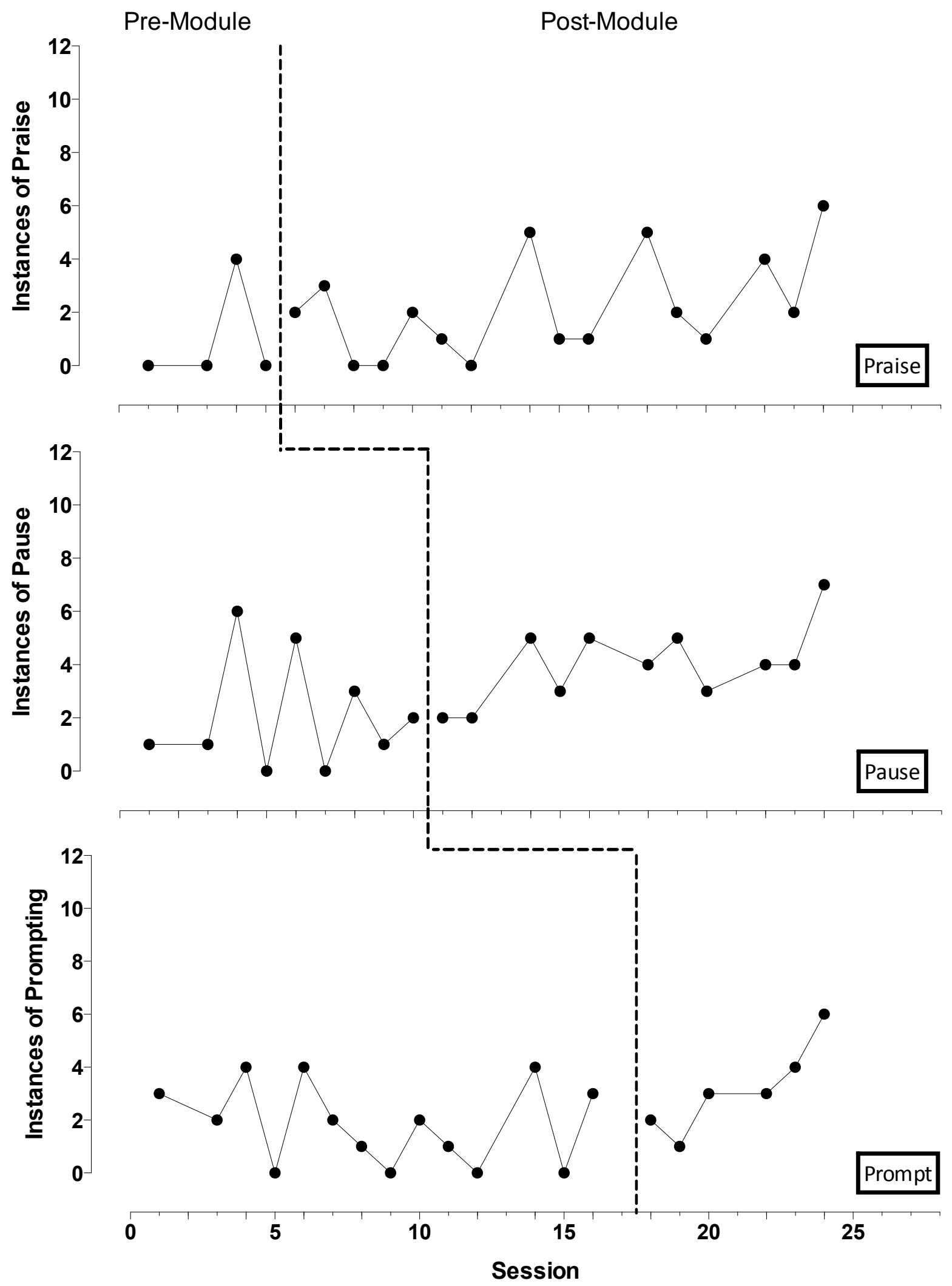

Figure 3. Cecelia's data. 
Prompts. Cecelia's instances of accurate use of prompts were highly variable during baseline with a slightly decreasing trend $(M=1.86$, range $=0-4)$. After receiving the prompt module training, Cecelia's instances of accurate use of prompts demonstrated a steadily accelerating trend with $16.67 \%$ non-overlapping data points. The level of instances of correct prompts increased well above baseline $(M=3.17$, range $=1-6)$.

Summary. Cecelia demonstrated highly variable use of praise, pause, and prompts during baseline. Although this variability continued after completing the praise training module, Cecelia increased consistency of accurate use of pause. Cecelia's absences on sessions 21, 23, and 25 following completion of the prompts module made it difficult to make substantive determinations of the efficacy of the training module, but the limited data show accelerating trends post-module and suggested some skill gains.

\section{Discussion}

There is a clear need for paraeducator training (Giangreco \& Broer, 2005; Giangreco et al., 2001; Maggin et al., 2012; Tompkins et al., 2012). Without effective training on instructional practices, paraeducators may not be able to support the classroom teacher effectively (Bingham et al., 2007; Douglas et al., 2013; Feldman \& Matos, 2013; O'Keeffe et al., 2013; Rispoli et al., 2011; Tompkins et al., 2012). Because paraeducators have become increasingly vital participants in school communities and their roles and responsibilities continue to grow, the purpose of this study was to evaluate the effectiveness of a user-friendly, low-cost training module designed to increase paraeducators' accurate use of three instructional strategies in the classroom (i.e., praise, pause, and prompts).

Overall results indicated that all participants demonstrated some level of increase in accurate use of the instructional strategies. Specifically, there was an increase in accurate use of praise and pause following the module training and two participants (Amy and Bev) increased their accurate use of prompts above baseline. Although all participants made some gains after the training, it was clear that participants were still inconsistent in their use of these instructional strategies. Participants used some strategies at higher levels following training, but often continued to show variability in their accurate use of these skills. These results are consistent with the literature on behavior-specific praise that suggests it is a skill that does not come naturally, and, even after taught, can be resistant to change (Sutherland et al., 2000). Likewise, there is evidence that indicates pause (wait-time) can be challenging to employ (Johnson \& Parker, 2013; Maroni, 2011; Rhoades, 2013). In fact, it has been suggested that this practice is difficult to master due to adult comfort level when using non-verbal language, but can be learned through sufficient practice (Rhoades, 2013).

Despite the accelerating change in Cecelia's use of prompts, the prompt module elicited the most questions from participants and was the weakest in changing skill usage across participants. Participants' questions on this module focused specifically on the modeling component of prompting, which paraeducators commented was used less frequently with the population of students in their classroom settings (i.e., students with significant disabilities in conjunction with specific health-care needs). Still, the reason for participants' questions on this module is unclear. It can be speculated that these questions may have been posed due to (a) potential better 
understanding of the content prior to the implementation of this module, (b) possibility of the module simply being unclear in certain areas, or (c) probability that participants felt comfortable with the research assistants following the third module. In the future, it will be important to assess the role of familiarity with the trainer on participant outcomes and receptivity to training.

While all participants made some gains, it is clear that not all responded equally to the training. Bev, despite having the fewest years of experience, provided the highest social validity ratings of the three participants both at baseline and post-intervention. Perhaps Bev's responses were influenced by her expectations and investment in the modules, whereas the other participants' responses may have been swayed by lower expectations, as evidenced by their lower social validity ratings. Interestingly, the literature suggests that paraeducators are invested in training and enhancing their skills (Breton, 2010; Butt \& Lowe, 2012; Carter et al., 2009; Feldman \& Matos, 2013; Griffin-Shirley \& Matlock, 2004). Nonetheless, it is clear that the study's social validity was somewhat weak. Despite the lack of buy-in and the paraeducators' low ratings of the training, results suggested that the modules may have contributed at some level to some of the increase in participants' rate of accurate use of the three instructional strategies.

\section{Implications}

The current study adds to the research base on paraeducator training by corroborating the comments of Causton-Theoharis and Malmgren (2005) that training does not need to be timeintensive or expensive to be effective. The training modules offered a unique and cost-effective way to train paraeducators in core instructional strategies. The effectiveness of the delivery of these training modules was consistent with suggested methods of training (Brock \& Carter, 2013; Feldman \& Matos, 2013; Maggin et al., 2012; McCulloch \& Noonan, 2013). Unfortunately, the low social validity ratings by the participants may suggest that paraeducators do not value the importance of these practices due to previous exposure, overall experience in the classroom setting, and/or other practices modeled by their supervising teacher. Furthermore, results of this study suggested that paraeducator buy-in on the training may be key to the impact of training on their use of skills. Participants responded differently to the modules with some increase in use of strategies by two of the three participants. This change in the implementation of these practices may suggest that the 30 to 40 minute PowerPoint ${ }^{\mathrm{TM}}$ training module may have had some influence on the participants' use of these instructional practices. Although variability existed in the performance of participants across the three instructional strategies, it was clear that the participants demonstrated higher appropriate use of the strategies during some sessions post intervention than at baseline. In the future, it would be interesting to add a second part to each module as a booster to determine whether increased training would decrease variability in use of strategies and help stabilize use at a higher level for each participant. In other words, consideration of ways to increase the efficacy of this low-cost training method may be worthwhile to enhance effective instruction and interactions of paraeducators with students with disabilities.

\section{Limitations}

While there were some positive outcomes of this module-based training, limitations should be noted related to data collection, generalization of findings, paraeducator enjoyment of the 
modules, and potential history effects that may have influenced the findings. First, modules were not evaluated for validity prior to implementing the study. Future research should consider evaluating validity of the content and structure of the modules by experts in the field.

Another limitation was scheduling. Scheduling was bound by the school calendar and schoolwide activities requiring the use of a more compressed design than was desirable. A widely dispersed delivery of each module to create a staggered multiple-baseline design across participants and behaviors could have been employed. Initially, it was decided not to vary the order in which participants completed the modules due to concerns that there would be diffusion of treatment because of the relationships between paraeducators in this setting. In fact, anecdotal data indicated that participants in the study shared information with paraeducators who were not part of the study.

Another limitation was that maintenance data were not collected on accurate strategy use a month or more out from the training. While fidelity of implementation data on performance feedback were collected during the delivery of the modules, the performance feedback implementation data were evaluated as a package, not as individual components. Consideration of these various components would have allowed a more precise evaluation of fidelity of implementation specifically targeting the feedback.

Lastly, this study did not address whether teachers within the classroom already used and modeled these strategies to their paraeducators; hence a question remains if participants had preexposure to these strategies. Although several special education teachers at the school were informally asked about the importance of their paraeducators having skill in praise, pause, and prompts, data on skills needed by paraeducators across all teachers were not collected nor were data collected on social validity from classroom teachers or administrators. This would likely have been valuable information to better understand the value of the training modules to all stakeholders, as well as the buy-in on the training of these specific instructional strategies.

\section{Future Research}

Findings of this study suggested that investing 30 to 40 minutes for a targeted training session may have positive effects on paraeducators' instructional interactions with students with disabilities. However, future research is needed to determine if the variability in paraeducator performance decreases when providing training during a more structured school schedule. Additionally, attention should be given to the evaluation of other methods of paraeducator training. The fact that participants in this study shared content they learned in the modules with colleagues suggested that further investigation of paraeducator learning networks and supports may be worthwhile. Furthermore, expansion of the study on a larger scale for full-school use as well as evaluation across settings would increase our knowledge of the utility of the modulebased training given that paraeducators work with students with a wide range of disabilities (e.g., autism, intellectual disabilities, behavior disorders). 


\section{Final Thoughts}

There is agreement that paraeducator training is essential not only to support teachers, but also to increase students' access to effective educational experiences (Giangreco, Suter, \& Doyle, 2010; Rispoli et al., 2011; Tompkins et al., 2012). Increased use of paraeducator supports in school environments highlights the importance and timeliness of research in this area. It is unfair and unrealistic to expect paraeducators to provide high-quality instructional supports to teachers and students without adequate training. Hence, training in instructional practices is essential not only for paraeducators, but also for program development considerations in teacher preparation. Future special education teachers should have a clear understanding of the various roles (e.g., training, supervision) they will have when working with support staff in the classroom. Lastly, based on the results from this study and those from the Causton-Theoharis and Malmgren (2005) study, one can make the assumption that it is likely that training for paraeducators can be costeffective, time-efficient, and have positive effects on not only paraeducator performance, but also on classroom teachers and students within these settings.

\section{References}

Aykut, Ç. (2012). Effectiveness and efficiency of constant-time delay and most-to-least prompt procedures in teaching daily living skills to children with intellectual disabilities. Kuram Ve Uygulamada Ĕ̈itim Bilimleri, 12(1), 366-373.

Bingham, M. A., Spooner, F., \& Browder, D. (2007). Training paraeducators to promote the use of augmentative and alternative communication by students with significant disabilities. Education and Training in Developmental Disabilities, 42, 339-352.

Bolton, J., \& Mayer, M. D. (2008). Promoting the generalization of paraprofessional discrete trial teaching skills. Focus on Autism and Other Developmental Disabilities, 23, 103-111. http://dx.doi.org/10.1177/1088357608316269

Breton, W. (2010). Special education paraprofessionals: Perceptions of preservice preparation, supervision, and ongoing developmental training. International Journal of Special Education, 25, 34-45.

Brock, M. E., \& Carter, E. W. (2013). Effects of a professional development package to prepare special education paraprofessionals to implement evidence-based practice. The Journal of Special Education. Advance online publication. http://dx.doi.org/10.1177/0022466913501882

Browder, D. M., \& Spooner, F. (2011). Teaching students with moderate and severe disabilities. New York: Guildford Press.

Butt, R., \& Lowe, K. (2012). Teaching assistants and class teachers: Differing perceptions, role confusion and the benefits of skills-based training. International Journal of Inclusive Education, 16(2), 207-219. http://dx.doi.org/10.1080/13603111003739678 
Carter, E., O'Rourke, L., Sisco, L. G., \& Pelsue, D. (2009). Knowledge, responsibilities, and training needs of paraprofessionals in elementary and secondary schools. Remedial and Special Education, 30(6), 344-359. http://dx.doi.org/10.1177/0741932508324399

Causton-Theoharis, J. N., \& Malmgren, K. W. (2005). Increasing peer interactions for students with severe disabilities via paraprofessional training. Exceptional Children, 71, 431-444.

Council for Exceptional Children and National Resource Center for Paraeducators. (2011, September 12). Special education paraeducator common core specialty set for PSPC. Retrieved from http://sped.org/Standards/Paraeducator-Preparation-Guidelines

Da Fonte, M. A., \& Capizzi, A. M. (2015). Working collaboratively with support staff for inclusive education. In Working with teaching assistants and other support staff for inclusive education (p. 195-218). Book series: International Perspectives on Inclusive Education; Volume 4. Bingley, United Kingdom: Emerald Group Publishing. http://dx.doi.org/10.1108/s1479-363620150000004010

Douglas, S. N., McNaughton, D., \& Light, J. (2013). Online training for paraeducators to support the communication of young children. Journal of Early Intervention, 35(3), 223-242. http://dx.doi.org/10.1177/1053815114526782

Duchaine, E. L., Jolivette, K., \& Fredrick, L. D. (2011). The effect of teacher coaching with performance feedback on behavior-specific praise in inclusion classrooms. Education and Treatment of Children, 34(2), 209-227. http://dx.doi.org/10.1353/etc.2011.0009

Englert, C. S., Tarrant, K. L., \& Mariage, T. V. (1992). Defining and redefining instructional practice in special education: Perspectives on good teaching. Teacher Education and Special Education, 15, 62-87. http://dx.doi.org/10.1177/088840649201500203

Ephratt, M. (2008). The functions of silence. Journal of Pragmatics: An Interdisciplinary Journal of Language Studies, 40(11), 1909-1938. http://dx.doi.org/10.1016/j.pragma.2008.03.009

Feldman, E. K., \& Matos, R. (2013). Training paraprofessionals to facilitate social interactions between children with autism and their typically developing peers. Journal of Positive Behavior Interventions, 15(3), 169-179. http://dx.doi.org/10.1177/1098300712457421

Fisher, M., \& Pleasants, S. L. (2012). Roles, responsibilities, and concerns of paraeducators: Findings from a statewide survey. Remedial and Special Education, 33(5), 287-297. http://dx.doi.org/10.1177/0741932510397762

Fullerton, E. K., Conroy, M. A., \& Correa, V. I. (2009). Early childhood teachers' use of specific praise statements with young children at risk for behavioral disorders. Behavioral Disorders, 34, 118-135. 
Giangreco, M. F., Backus, L., CichoskiKelly, E., Sherman, P., \& Mavropoulos, Y. (2003). Paraeducator training materials to facilitate inclusive education: Initial field-test data. Rural Special Education Quarterly, 22, 17-27.

Giangreco M. F., \& Broer, S. M. (2005) Questionable utilization of paraprofessionals in inclusive schools: Are we addressing symptoms or causes. Focus on Autism and Other Developmental Disabilities 20, 10-26. http://dx.doi.org/10.1177/10883576050200010201

Giangreco, M. F., Edelman, S. W., Broer, S. M., \& Doyle, M. (2001). Paraprofessional support of students with disabilities: Literature from the past decade. Exceptional Children, 68, 45-63. http://dx.doi.org/10.1177/001440290106800103

Giangreco, M. F., Suter, J. C., \& Doyle, M. B. (2010). Paraprofessionals in inclusive schools: A review of recent research. Journal of Educational and Psychological Consultation, 20, 41-57. http://dx.doi.org/10.1080/10474410903535356

Goeke, J. L. (2009). Explicit instruction: A framework for meaningful direct instruction. Upper Saddle River, NJ: Merrill.

Griffin-Shirley, N., \& Matlock, D. (2004). Paraprofessionals speak out: Survey. RE:View, 36(3), 127-136. http://dx.doi.org/10.3200/revu.36.3.127-136

Johnson, N., \& Parker, A. T. (2013). Effects of wait time when communicating with children who have sensory and additional disabilities. Journal of Visual Impairment and Blindness, 107(5), 363.

Kalis, T. M., Vannest, K. J., \& Parker, R. (2007). Praise counts: Using self-monitoring to increase effective teaching practices. Preventing School Failure, 51(3), 20-27. http://dx.doi.org/10.3200/PSFL.51.3.20-27

Kennedy, C. H. (2005). Single-case designs for educational research. Boston, MA: Allyn and Bacon.

Koegel, R. L., Kim, S., \& Koegel, L. K. (2014). Training paraprofessionals to improve socialization in students with ASD. Journal of Autism and Developmental Disorders, 44(9), 2197-208. http://dx.doi.org/10.1007/s10803-014-2094-x

Lane, K. L., Fletcher, T., Carter, E. W., Dejud, C., \& Delorenzo, J. (2007). Paraprofessional-led phonological awareness training with youngsters at risk for reading and behavioral concerns. Remedial and Special Education, 28, 266-276. http://dx.doi.org/10.1177/07419325070280050201

Ledford, J. R., Lane, J. D., Elam, K. L., \& Wolery, M. (2012). Using response-prompting procedures during small group direct instruction: Outcomes and procedural variations. American Journal on Intellectual and Developmental Disabilities, 117(5), 413-434. http://dx.doi.org/10.1352/1944-7558-117.5.413 
Maggin, D. M., Fallon, L. M., Sanetti, L. M. H., \& Ruberto, L. M. (2012). Training paraeducators to implement a group contingency protocol: Direct and collateral effects. Behavioral Disorders, 38(1), 18-37.

Martens, B. K., Witt, J. C., Elliot, S. N., \& Darveaux, D. X. (1985). Teacher judgments concerning the acceptability of school-based intervention. Professional Psychology: Research and Practices, 16(2), 191-198. http://dx.doi.org/10.1037/0735-7028.16.2.191

Maroni, B. (2011). Pauses, gaps and wait time in classroom interaction in primary schools. Journal of Pragmatics, 43(7), 2081-2093. http://dx.doi.org/10.1016/j.pragma.2010.12.006

Matthews, K., \& Hagopian, L. (2014). A comparison of two data analysis training methods for paraprofessionals in an educational setting. Journal of Organizational Behavior Management, 34(2), 165-178. http://dx.doi.org/10.1080/01608061.2014.912974

McCulloch, E. B., \& Noonan, M. J. (2013). Impact of online training videos on the implementation of mand training by three elementary school paraprofessionals. Education and Training in Autism and Developmental Disabilities, 48(1), 132-141.

Morse, T. E., \& Schuster, J. W. (2004). Simultaneous prompting: A review of the literature. Education and Training in Developmental Disabilities, 39(2), 153-168.

O'Keeffe, B. V., Slocum, T. A., \& Magnusson, R. (2013). The effects of a fluency training package on paraprofessionals' presentation of a reading intervention. Journal of Special Education, 47(1), 14-27. http://dx.doi.org/10.1177/0022466911404072

Partin, T. C. M., Robertson, R. E., Maggin, D. M., Oliver, R. M., \& Wehby, J. H. (2009). Using teacher praise and opportunities to respond to promote appropriate student behavior. Preventing School Failure: Alternative Education for Children and Youth, 54, 172-178. http://dx.doi.org/10.1080/10459880903493179

Petscher, E. S., \& Bailey, J. S. (2006). Effects of training, prompting, and self-monitoring on staff behavior in a classroom for students with disabilities. Journal of Applied Behavior Analysis, 39, 215-226. http://dx.doi.org/10.1901/jaba.2006.02-05

Quilty, K. M. (2007). Teaching paraprofessionals how to write and implement social stories for students with autism spectrum disorders. Remedial and Special Education, 28(3), 182189. http://dx.doi.org/10.1177/07419325070280030701

Reinke, W. M., Lewis-Palmer, T., \& Merrell, K. (2008). The classroom check-up: A classwide teacher consultation model for increasing praise and decreasing disruptive behavior. School Psychology Review, 37(3), 315-332. 
Rhoades, E. A. (2013). Interactive silences: Evidence for strategies to facilitate spoken language in children with hearing loss. The Volta Review, 113(1), 57-73.

Rispoli, M., Neely, L., Lang, R., \& Ganz, J. (2011). Training paraprofessionals to implement interventions for people with autism spectrum disorders: A systematic review. Developmental Neurorehabilitation, 14(6), 378-388. http://dx.doi.org/10.3109/17518423.2011.620577

Rowe, M. B. (1986). Wait time: Slowing down may be a way of speeding up! Journal of Teacher Education, 37, 43-50. http://dx.doi.org/10.1177/002248718603700110

Scruggs, T. E., \& Mastropieri, M. A. (2013). PND at 25: Past, present, and future trends in summarizing single-subject research. Remedial and Special Education, 34, 9-19. http://dx.doi.org/10.1177/0741932512440730

Scruggs, T. E., Mastropieri, M. A., \& Casto, G. (1987). The quantitative synthesis of single subject research: Methodology and validation. Remedial and Special Education, 8(2), 24-33. http://dx.doi.org/10.1177/074193258700800206

Sutherland, K. S., Alder, N., \& Gunter, P. L. (2003). The effect of varying rates of opportunities to respond to academic requests on the classroom behavior of students with EBD. Journal of Emotional and Behavioral Disorders, 11(4), 239-248. http://dx.doi.org/10.1177/10634266030110040501

Sutherland, K. S., Wehby, J. H., \& Copeland, S. R. (2000). Effect of varying rates of behaviorspecific praise on the on-task behavior of students with EBD. Journal of Emotional and Behavioral Disorders, 8, 2-8. http://dx.doi.org/10.1177/106342660000800101

Tincani, M., \& Crozier, S. (2008). Comparing brief and extended wait-time during small group instruction for children with challenging behaviors. Journal of Behavioral Education, 16(4), 79-92. http://dx.doi.org/10.1007/s10864-008-9063-4

Tompkins, R. H., Ratcliff, N., Jones, C., Vaden, S. R., Hunt, G., \& Sheehan, H. C. (2012). The myth of the foolproof script: Can paraprofessionals effectively improve kindergarten student achievement using a scripted phonics program? Early Years: An International Journal of Research and Development, 32(3), 313-323. http://dx.doi.org/10.1080/09575146.2011.651712

van Vonderen, A., \& de Bresser, A. (2005). The effect of supervisory feedback, self-recording, and graphic feedback on trainer behavior during one-to-one training. Behavioral Interventions, 20, 273-284. http://dx.doi.org/10.1002/bin.198

Vuran, S. (2008). Empowering leisure skills in adults with autism: An experimental investigation through the most to least prompting procedure. International Journal of Special Education, 23, 174-181. 
Walker, G. (2008). Constant and progressive time delay procedures for teaching children with autism: A literature review. Journal of Autism and Developmental Disorders, 38(2), 261275. http://dx.doi.org/10.1007/s10803-007-0390-4

West, E. A., \& Billingsley, F. (2005). Improving the system of least prompts: A comparison of procedural variations. Education and Training in Developmental Disabilities, 40(2), 131144.

Westling, D. L., \& Fox, L. (2009). Teaching students with severe disabilities ( $4^{\text {th }}$ Ed.). Upper Saddle River, NJ: Pearson.

Wolery, M., Anthony, L., Caldwell, N. K., Snyder, E. D., \& Morgante, J. D. (2002). Embedding and distributing constant time delay in circle time and transitions. Topics in Early Childhood Special Education, 22(1), 14-25. http://dx.doi.org/10.1177/027112140202200102

Yanardağ, M., Birkan, B., Yılmaz, İ., Konukman, F., Ağbuğa, B., \& Lieberman, L. (2011). The effects of least-to-most prompting procedure in teaching basic tennis skills to children with autism. Kinesiology, 43(1), 44-55.

Authors' note: The authors would like to thank Gwendolyn Diamond, Anne Schostek, and Mary Rose White for their technical assistance and feedback in developing this manuscript. Address correspondence concerning this article to M. Alexandra Da Fonte, Department of Special Education, Vanderbilt University, Box 228, 230 Appleton Place, Nashville, TN 372035721, United States; e-mail: Alexandra.Dafonte@vanderbilt.edu; phone: (615) 322-8898. 